\title{
Treatment of COMPLiCATED INTRA-ABDOMINAL INFECTIONS IN THE Era of Multi-Drug Resistant Bacteria
}

\author{
T. Herzog, A. M. Chromik, W. Uhl \\ Department of Surgery, St. Josef Hospital, Ruhr University Bochum, Germany
}

\begin{abstract}
The management of severe intra-abdominal infections remains a major challenge facing surgeons and intensive care physicians, because of its association with high morbidity and mortality. Surgical management and intensive care medicine have constantly improved, but in the recent years a rapidly continuing emergence of resistant pathogens led to treatment failure secondary to infections with multi-drug resistant bacteria. In secondary peritonitis the rate of resistant germs at the initial operation is already $30 \%$. The lack of effective antibiotics against these pathogens resulted in the development of new broad-spectrum compounds and antibiotics directed against resistant germs. But so far no "super-drug" with efficacy against all resistant bacteria exists. Even more, soon after their approval, reports on resistance against these novel drugs have been reported, or the drugs were withdrawn from the market due to severe side effects. Since pharmaceutical companies reduced their investigations on antibiotic research, only few new antimicrobial derivates are available.

In abdominal surgery you may be in fear that in the future more and more patients with tertiary peritonitis secondary to multi-drug resistant species are seen with an increase of mortality after secondary peritonitis.

This article reviews the current treatment modalities for complicated intra-abdominal infections with special reference to the antibiotic treatment of complicated intra-abdominal infections with multi-drug resistant species.
\end{abstract}

Key words: antibiotic treatment, multi-drug resistance, intra-abdominal infection

\section{Abbreviations:}

cIAI Complicated intra-abdominal infection

ESBL Extended spectrum B-lactamase

IAI Intra-abdominal infection

ICU Intensive care unit

MRSA Methicillin resistant staphylococcus aureus

SP Secondary peritonitis

spp. Species

TP Tertiary peritonitis

VRE Vancomycin resistant Enterococcus

\section{HISTORICAL BACKGROUND}

One-hundred years ago complicated intra-abdominal infections (cIAIs) were associated with mortality rates of $90 \%$ [1]. During the last century more aggressive surgical methods, intensive care management and the availability of a large diversity of differently acting antibiotics have reduced mortality below $25 \%$ [2]. But at the end of the first decade of the $21^{\text {st }}$ century cIAIs remain responsible for $20 \%$ of severe sepsis in intensive care units (ICU). Thus cIAIs represent the second common cause for infectious morbidity and mortality after pneumonia [3, 4].

The treatment of cIAI is based on a few simple principles, including focus elimination, lavage concepts, intensive care medicine and application of antibiotics [5]. While innovative surgical techniques and intensive care management constantly improved treatment modalities for critical ill patients, the development of new potent antibiotics was unable to follow the rapidly increasing number of resistant germs [6-8]. To assure the high quality in the management of cIAIs, surgeons will need substantial help of new antimicrobial compounds.

\section{Classification}

Complicated intra-abdominal infections are usually defined as abscess formation or peritonitis beyond the origin of the perforation of a hollow viscus into the peritoneal cavity, requiring an invasive procedure for source control [9]. Although the term intra-abdominal infection (IAI) is often synonymously used with the term peritonitis, there is a wide variation in the severity of illness for the different forms and origins of peritonitis. The mortality for patients with appendicitis ranges between $5 \%$ and $9 \%$, while the mortality for gastric ulcer perforation is $21 \%$ and ranges from $45 \%$ to $50 \%$ for large bowel perforation or peritonitis originating from the biliary tract $[1,10,11]$.

Peritonitis includes the local reaction of the organ "peritoneum" and the patients' systemic inflammatory response to micro-organisms and their toxins. Thus, peritonitis needs a clear differentiation from bacterial contamination, e.g. in acute cholecystitis or gan- 
Table 1. Forms of peritonitis, according to [12].

\begin{tabular}{|c|c|c|}
\hline & Causes of peritonitis & Most common bacterial species \\
\hline $\begin{array}{l}\text { Primary bacterial } \\
\text { peritonitis }\end{array}$ & $\begin{array}{l}\text { Peritoneal infection without anatomic barrier disruption; } \\
\text { most common in patients with cirrhosis or severe immune } \\
\text { dysfunction or early childhood }\end{array}$ & $\begin{array}{l}\text { Gram negative Enterobacteriaceae, } \\
\text { Streptococcus spp. }\end{array}$ \\
\hline $\begin{array}{l}\text { Secondary bacterial } \\
\text { peritonitis }\end{array}$ & $\begin{array}{l}\text { Peritoneal infection with perforation of the gut wall and } \\
\text { spillage of bacteria into the peritoneal cavity. This peritonitis } \\
\text { may be health care associated or community-acquired }\end{array}$ & $\begin{array}{l}\text { Polymicrobial infection with Gram- } \\
\text { negative Enterobacteriaceae, Gram- } \\
\text { positive Enterococci, Staphylococci and } \\
\text { anaerobes }\end{array}$ \\
\hline Tertiary peritonitis & $\begin{array}{l}\text { Persistent or recurrent infection after "adequate" treatment } \\
\text { of primary or secondary peritonitis; most common in patients } \\
\text { with severe co-morbidities or compromised immune function }\end{array}$ & $\begin{array}{l}\text { Polymicrobial infections like in } \\
\text { secondary peritonitis, but more likely to } \\
\text { involve resistant bacteria }\end{array}$ \\
\hline
\end{tabular}

grenous appendicitis, where local spillage of bacteria into the abdominal cavity occurs, but infection is not established.

Usually peritonitis is classified into primary, secondary (SP) and tertiary peritonitis (TP); (Table 1, forms of peritonitis) [12]. Primary peritonitis, also referred to as spontaneous peritonitis, arises without derangement of anatomical barriers and has a low incidence on surgical wards.

The most frequent entity is SP, which is defined as infection of the peritoneal cavity resulting from perforation, breakdown of an intestinal anastomosis, ischemic necrosis or other injuries of the gastro-intestinal tract [12]. According to the mode of acquisition $\mathrm{SP}$ is divided into community-acquired and hospital associated infections. Community-acquired peritonitis is associated with bacterial stains originating from the source of the infection, although today community acquired infections with resistant species are a common and serious problem [13]. Usually patients with health care associated peritonitis have a higher probability of infections with opportunistic nosocomial facultative pathogenic bacteria and fungi. The diversity of different micro-organisms isolated in nosocomial infections is higher, while susceptibility among these strains is lower compared to community-acquired infections [14].

TP is less common and is defined as a severe or recurrent or persistent IAI after apparently successful and adequate surgical source control of SP [12]. TP is always a nosocomial infection, typically associated with high morbidity and mortality due to prolonged systemic inflammation, systemic inflammatory response syndrome, sepsis, severe sepsis or septic shock $[15,16]$. While the mortality of SP is less than $25 \%$, mortality for patients with TP is higher than $50 \%[8$, $17,18]$. Although the reasons for the development of TP are not completely understood, the high mortality in TP may reflect its association with more virulent species. Figure 1 illustrates the infection source of patients who developed TP after successful treatment of SP (Fig. 1, causes for SP and TP in surgical ICU patients) [18].

\section{Type of InFECTION AND MODE OF ACQUisition IndiCATES PATHOGENS}

Primary peritonitis is usually a mono-microbial infection with Gram-positive Cocci or Enterobacteriaceae. The etiology implies a conservative management, since primary peritonitis occurs spontaneously without perforation of a hollow viscus [19].

The species in SP and TP most frequently represent mixtures of Gram-positive and Gram-negative aerobes and anaerobes as well as fungi in certain cases of TP or in patients with immune suppression $[20,21]$. In community-acquired SP facultative and obligate aerobic Gram-negative and Gram-positive organisms must be considered in infections originating from the stomach, duodenum, biliary system and the small bowel (Table 2, Micro-organisms in peritonitis) [20, 22]. Ulcer perforations are usually associated with infections with E. coli
Causes for SP and TP in surgical ICU patients

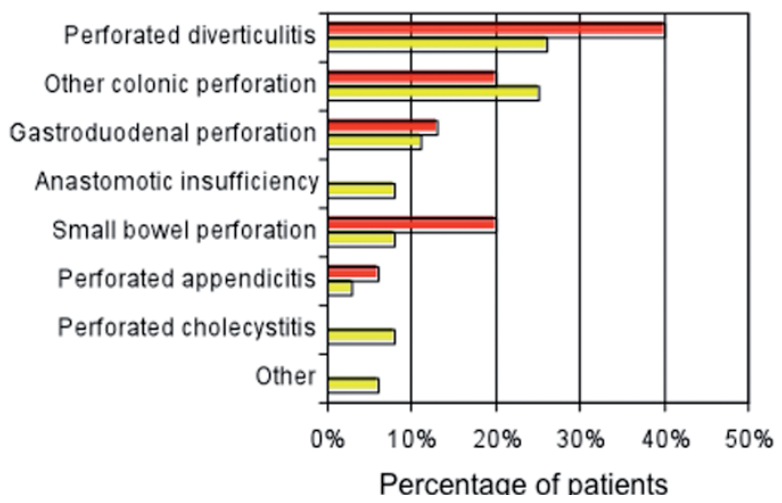

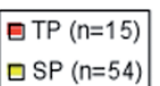

Fig. 1. Causes for SP and TP in surgical ICU patients, modified by [18]. Infection source for patients with SP at the index operation, who further developed TP ( $\mathrm{n}=15$, red bars) and for patients who did not (SP, $\mathrm{n}=54$, yellow bars). 
Table 2. Micro-organisms in peritonitis, according to [20].

\begin{tabular}{|c|c|c|c|c|c|c|c|}
\hline & $\begin{array}{l}\text { Gastro- } \\
\text { duodenal }\end{array}$ & $\begin{array}{c}\text { Biliary } \\
\text { tract }\end{array}$ & $\begin{array}{c}\text { Small } \\
\text { or large } \\
\text { bowel }\end{array}$ & Appendicitis & Abscess & Liver & Spleen \\
\hline \multicolumn{8}{|l|}{ Common aerobes } \\
\hline \multicolumn{8}{|l|}{ Gram-positive } \\
\hline Streptococcus spp. & $\mathrm{X}$ & $\varnothing$ & $\varnothing$ & $\varnothing$ & $\varnothing$ & $\varnothing$ & $\mathrm{X}$ \\
\hline Enterococcus spp. & $\varnothing$ & $\mathrm{X}$ & $\varnothing$ & $\varnothing$ & $\mathrm{X}$ & $\mathrm{X}$ & $\varnothing$ \\
\hline Staphylococcus spp. & $\varnothing$ & $\varnothing$ & $\varnothing$ & $\varnothing$ & $\varnothing$ & $\varnothing$ & $\mathrm{X}$ \\
\hline \multicolumn{8}{|l|}{ Gram-negative } \\
\hline E. coli & $\mathrm{X}$ & $\mathrm{X}$ & $\mathrm{X}$ & $\mathrm{X}$ & $\mathrm{X}$ & $\mathrm{X}$ & $\varnothing$ \\
\hline Enterobacter spp. & $\varnothing$ & $\varnothing$ & $\varnothing$ & $\varnothing$ & $\varnothing$ & $\varnothing$ & $\varnothing$ \\
\hline Pseudomonas spp. & $\varnothing$ & $\varnothing$ & $\varnothing$ & $\mathrm{X}$ & $\varnothing$ & $\varnothing$ & $\varnothing$ \\
\hline Klebsiella spp. & $\varnothing$ & $\mathrm{X}$ & $\mathrm{X}$ & $\varnothing$ & $\mathrm{X}$ & $\mathrm{X}$ & $\varnothing$ \\
\hline Proteus spp. & $\varnothing$ & $\varnothing$ & $\mathrm{X}$ & $\varnothing$ & $\varnothing$ & $\varnothing$ & $\varnothing$ \\
\hline Other & $\varnothing$ & $\varnothing$ & $\varnothing$ & $\varnothing$ & $\varnothing$ & $\varnothing$ & $\varnothing$ \\
\hline \multicolumn{8}{|l|}{ Common anaerobes } \\
\hline Bacteroides spp. & $\varnothing$ & $(\mathrm{X})$ & $\mathrm{X}$ & $\mathrm{X}$ & $\mathrm{X}$ & $(\mathrm{X})$ & $\varnothing$ \\
\hline Clostridium spp. & $\varnothing$ & $(\mathrm{X})$ & $\mathrm{X}$ & $\varnothing$ & $\mathrm{X}$ & $\varnothing$ & $\varnothing$ \\
\hline Anaerobe Cocci & $\varnothing$ & $\varnothing$ & $(\mathrm{X})$ & $\varnothing$ & $(\mathrm{X})$ & $\varnothing$ & $\varnothing$ \\
\hline
\end{tabular}

Legends: $\mathrm{X}=$ most frequent species; $\varnothing=$ usually not present; $(\mathrm{X})=$ rarely present

or Streptococci. Typical bacteria in biliary tract associated SP are E. coli, Klebsiella spp. and Enterococci. In small bowel derived infections Gram-negative aerobes and anaerobes are the most frequent pathogens. For infections originating from the colon all kinds of different aerobes and anaerobes must be considered.

The microbial flora encountered in health care associated IAIs and TP includes the same species as community-acquired SP with a shift towards opportunistic, nosocomial facultative pathogens and fungi. Frequent isolates include Enterobacteriaceae with extended spectrum $\beta$-lactamase (ESBL), Pseudomonas aeruginosa, Enterobacter spp., Enterococci, Methicillin resistant staphylococcus aureus (MRSA), Acinetobacter spp., Morganella morganii, Stenotrophomonas, coagulase-negative Staphylococci and different forms of Candida. Compared to community-acquired peritonitis the amount of micro-organisms with resistance mechanisms is higher among these species (Fig. 2 , germs in SP and TP) [18].

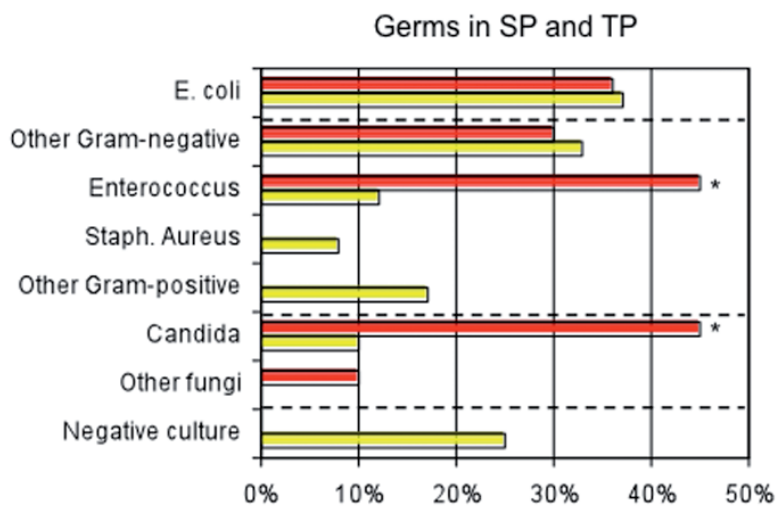

\section{RESISTANT GERMS}

One reason for the progressive amount of antibiotic resistance among bacteria is the inadequate and inappropriate use of antibiotics, as well as an increasing number of patients with severe co-morbidities. Today, patients often have a history of previous hospitalisation and broad-spectrum antibiotic exposure with selection of resistant pathogens [23]. Therefore, the rate of resistant micro-organisms in patients with hospital acquired SP ranges between $37 \%$ and $70 \%$ [24]. Several risk factors for infections with MDR germs have been identified (Table 3, risk factors for multi-drug resistance) [25-28].

At the end of the $20^{\text {th }}$ century most resistant species were found among Gram-positive bacteria, including MRSA and Vancomycin resistant Enterococci (VRE). In the last decade a shift towards a higher frequency of resistant Gram-negative bacteria occurred, especially among Enterobacteriaceae producing ESBL
Fig. 2. Germs in SP and TP, modified by [18]. Microbiological isolates in TP $(\mathrm{n}=11$, red bars), vs. SP ( $\mathrm{n}=54$, yellow bars). The microbial isolates of TP were obtained from the re-laparotomy that was diagnostic for TP. Isolates of SP were obtained at the index operation. The rate of Enterococcus and Candida was significantly higher in TP vs. SP $(* \mathrm{p} \leq 0.05)$. 
Table 3. Risk factors for MDR, modified by [24-27].

Risk factors for multi drug resistance

- High APACHE II score
- Longer preoperative hospitalisation
- Health care associated peritonitis
- Prior antibiotic treatment
- $\quad$ Longer postoperative antibiotic treatment
- Postoperative changes in antibiotic treatment
- Longer postoperative hospitalisation

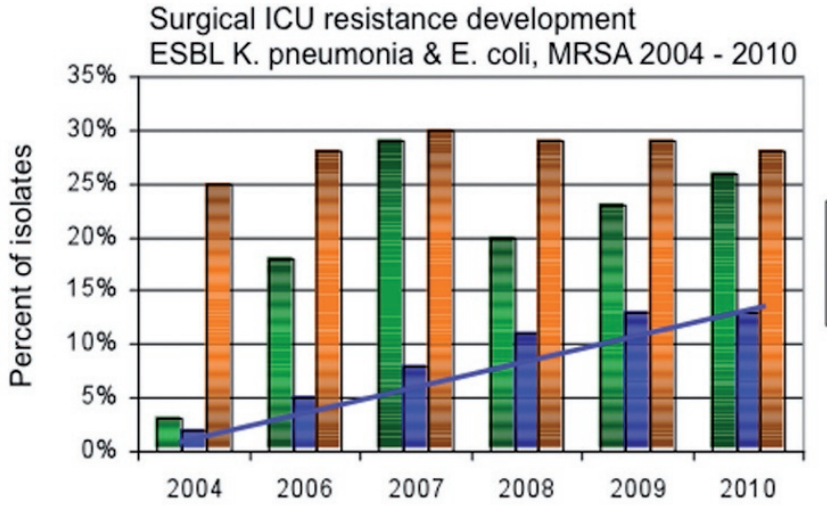

[29]. Figure 3 illustrates the development of resistant species in a surgical ICU (Fig. 3, surgical ICU resistance development).

A high prevalence for MRSA infections is observed in skin and soft structure infections, as well as in postoperative wound infections, while sepsis secondary to MRSA is most frequent in pneumonia and primary bacteremia [30-32]. Although less common in cIAIs, infections with MRSA should be considered in patients colonized with MRSA, hospital-acquired SP or TP or if risk other factors are present $[26,33]$.

Enterobacteriaceae are the most frequent isolates in cIAI and usually represent susceptible micro-organisms. Prior antibiotic therapy affects the development of ESBL, which is responsible for MDR, especially among Klebsiella spp., E. coli and Proteus spp. [29, 34, 35].

Enterococci are frequently isolated in patients with cIAIs. The need for specific therapy against Enterococci in SP has been discussed controversially, but isolation in ICU patients with health care associated SP or TP should always imply antibiotic treatment according to resistance analyses [36-40].

Pseudomonas aeruginosa is a common pathogen in pneumonia and in ICUs, but has also been frequently isolated in patients with appendicitis and peritoneal dialysis [4, 41, 42]. Although less frequent, the Gramnegative species Stenotrophomonas maltophilia, Morganella morganii and Acinetobacter spp. are responsible for a substantial part of MDR isolates in cIAIs [43].

Infections with fungi are less common in community-acquired infections, but should always be suspected
Table 4. Risk factors for treatment failure or death, modified by [920].

Independent risk factors for treatment failure or death in patients with cIAIs

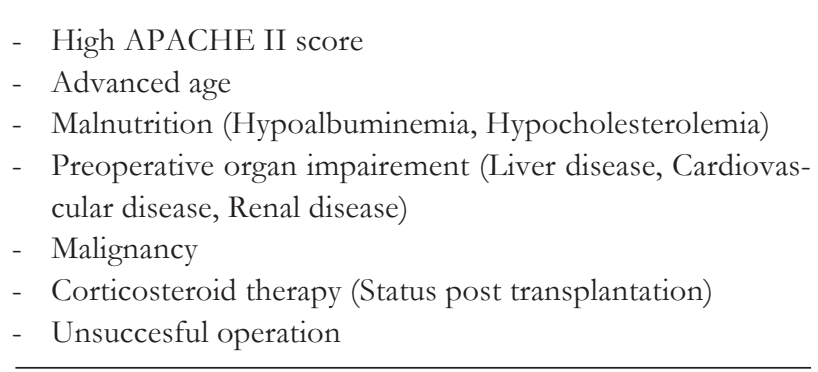

Fig. 3. Surgical ICU resistance development. Percentage of resistant pathogens among isolates. The blue line indicates the increasing rate of ESBL producing E. coli (blue bars), while the rate of ESBL producing Klebsiella pneumonia (green bars) and MRSA (orange bars) remains stable. (Own data, surgical ICU, St. Josef Hospital Bochum; Department for Medical Microbiology, University of Bochum).

in patients with immunodeficiency and prolonged antibacterial exposure [44].

\section{Risk FACTOR ANALYSES}

Infections with MDR pathogens are associated with a higher rate of treatment failure and mortality, but several other factors affect patients' outcome (Table 4, Risk factors for treatment failure or death) [9, 14, 20, $45,46]$. The only risk factor that is not based on patients' physiologic constitution is an unsuccessful operation. Thus, the inability to achieve adequate source control is predictive of mortality [2, 45, 47, 48]. Therefore, the fundamental basis in the treatment of cIAIs remains a successful operation, while intensive care management and antibiotic therapy are essential for post-operative stabilisation and final outcome of the individual patient.

The goal of patient adapted individual risk stratification should be to select a suitable antibiotic therapy to avoid the dilemma to be affronted with resistant micro-organisms after the return of the results from the microbiology. Therefore, assuming the patients risk for treatment failure is mandatory to optimise the individual initial treatment plan.

\section{Antibiotic Treatment OPTIONS}

For the antibiotic therapy of cIAIs a broad coverage against Gram-negative and Gram-positive species is generally recommended, but several treatment regimens lack activity against MDR bacteria. New antibiotics, with a narrower spectrum with special activity 
Table 5. Antimicrobial agents against MDR pathogens, modified by [49].

\begin{tabular}{lccccc}
\hline & MRSA & VRE & ESBL & Acinetobacter & Pseudomonas aeruginosa \\
\hline Ampicilin/Sulbactam & $\varnothing$ & $\varnothing$ & $\mathrm{X}$ & $\varnothing$ & $\varnothing$ \\
Piperacillin/Sulbactam & $\varnothing$ & $\varnothing$ & $\mathrm{X}$ & $\varnothing)$ & $\mathrm{X}$ \\
Glycopeptides (Vancomycin) & $(\mathrm{X}$ & $\varnothing$ & $\varnothing$ & $\varnothing$ & $\varnothing$ \\
Streptogramins (Quinupristin) & $\mathrm{X}$ & $\mathrm{X}$ & $\varnothing$ & $\varnothing$ & $\varnothing$ \\
Lipopeptides (Daptomycin) & $\mathrm{X}$ & $\mathrm{X}$ & $\varnothing$ & $\varnothing$ & $\varnothing$ \\
Oxazolidinones (Linezolid) & $\mathrm{X}$ & $\mathrm{X}$ & $\mathrm{X}$ & $\mathrm{X}$ & $\varnothing$ \\
B-lactams (Ceftobiprole) & $\mathrm{X}$ & $\mathrm{X})$ & $\mathrm{X})$ & $\varnothing$ \\
Carbapenemes (Doripenem) & $\mathrm{X})$ & $\mathrm{X})$ & $\mathrm{X})$ & $\varnothing$ \\
Glycylcycline (Tigecycline) & $\mathrm{X}$ & $\mathrm{X}$ & $(\mathrm{X})$ & $(\mathrm{X})$ & $\varnothing)$ \\
Quinolones & $\varnothing$ & $\varnothing$ & & $\varnothing$ & $\varnothing$ \\
\hline
\end{tabular}

Legends: $X=$ effective; $\varnothing=$ not effective; $(X)=$ partial activity

Table 6. Antibiotic treatment recommendations, according to [65].

\begin{tabular}{|c|c|c|}
\hline & Monotherapy & Combination therapy \\
\hline \multicolumn{3}{|l|}{ Diagnosis } \\
\hline \multicolumn{3}{|l|}{ Secondary peritonitis } \\
\hline low risk (localised peritonitis) & $\begin{array}{l}\text { Ampicillin/Sulbactam } \\
\text { Carbapenem }\end{array}$ & $\begin{array}{l}2^{\text {nd }} \text { generation Cephalosporin }+ \text { Metronidazol } \\
3^{\text {rd }} \text { generation Cephalosporin }+ \text { Metronidazol }\end{array}$ \\
\hline low risk (diffuse peritonitis) & $\begin{array}{l}\text { Ampicillin/Sulbactam } \\
\text { Piperacillin/Tazobactam } \\
\text { Carbapenem (group 1/2) } \\
\text { Fluorochinolon 4th generation } \\
\text { Tigecyclin }\end{array}$ & $\begin{array}{l}2^{\text {nd }} \text { generation Fluorochinolon }+ \text { Metronidazol } \\
3^{\text {rd }} \text { or } 4^{\text {th }} \text { generation Cephalosporin }+ \text { Metronidazol }\end{array}$ \\
\hline High risk & $\begin{array}{l}\text { Piperacillin/Tazobactam } \\
\text { Carbapenem (group 1/2) } \\
\text { Tigecyclin }\end{array}$ & $4^{\text {th }}$ generation Cephalosporin + Metronidazol \\
\hline Tertiary peritonitis & $\begin{array}{l}\text { According to resistance from } \\
\text { microbiology }\end{array}$ & Antifungal therapy in high risk patients \\
\hline
\end{tabular}

against MRSA and VRE have been developed, including quinupristin, daptomycin and oxazolidinones [4951]. While these drugs offer a new opportunity in the treatment of infections with these difficult to treat organisms, they have no activity against Gram-negative bacteria. But especially among Gram-negative bacteria the amount of resistant micro-organisms producing ESBL increases constantly, while the rate of infections with MRSA remains stable (Fig. 3, surgical ICU resistance development).

New drugs with activity against Gram-positive and Gram-negative resistant germs with special coverage of ESBL include tigecycline and $4^{\text {th }}$ generation $\beta$-lactam antibiotics [52-55]. Both derivates have broad spectrum activity against most pathogens commonly associated with cIAIs, but they do not have a reliable activity against pseudomonas aeruginosa $[56,57]$.

Although all these novelties offer an alternative in the presence of MDR species, each derivate has a weak point and no compound is able to cover all resistant pathogens (Table 5; Antimicrobial agents against MDR pathogens) [50, 58, 59]. In high risk patients with nosocomial cIAIs the empiric antimicrobial therapy should therefore be selected after consideration of the likelihood of difficult-to-treat isolates [60].
The only derivates with broad coverage against the expected flora in SP are Carbapenems, $\beta$-lactam antibiotics and tigecycline, since they provide coverage against both, Gram-negative and Gram-positive species. None of the new derivates with special activity against infections with MRSA and VRE (daptomycin and linezolid) covers ESBL, while Enterobacteriaceae with ESBL can be treated with Ampicillin/Sulbactam or Piperacillin/Tazobac. Carbapenems and $4^{\text {th }}$ generation $\beta$-lactam antibiotics have no reliable activity against VRE and MRSA. The only derivate covering MRSA, VRE and ESBL is tigecycline. The weak point of tigecycline is the lacking activity against Pseudomonas aeruginosa, while treatment with Carbapenems and Piperacillin/Sulbactam is effective against Pseudomonas aeruginosa.

\section{TREATMENT RECOMMENDATION}

Guidelines aimed at simplifying the antibiotic choice according to the severity of illness, but in fact most guidelines do not consider that there is a vast diversity of differently acting antibiotics [9, 61]. Most antibiotics are effective in preventing post-operative complications following peritonitis, but there is no evidence 
Table 7. "Tarragona strategy", according to [66].

Tarragona strategy

Look at your patient

Listen to your hospital

Hit hard and fast

Get to the point

Focus, focus, focus
The choice for a certain antibiotic treatment should be based on individual patients' risk factors

Knowledge of the actual hospital specific surveillance data is essential for the antibiotic choice

The therapy should be initiated immediately and be broad enough to reach the vast majority of likely pathogens

Select antibiotics with pharmacokinetic and-dynamic properties to reach effective concentration at the side of infection

Re-evaluation of the initial therapy after 3 days, depending on the results from the microbiology, providing the option of de-escalation to reduce selection pressure and costs to support that one regimen is superior to another. Controversially, regularly changes between the different compounds according to the hospital specific epidemiology are essential to avoid the development of resistant germs [62]. The initial empiric antibiotic therapy should be initiated immediately. Any delay of appropriate antibiotic treatment increases the probability of mortality [63-65].

Low risk patients with community-acquired SP still represent the largest group of patients with cIAIs. According to the intra-operative findings these patients should receive "narrow spectrum" agents, e.g. ampicillin/sulbactam or a $3^{\text {rd }}$ generation cephalosporines/ fluorochinolones and metronidazol for one or two days, if the peritonitis is localized and source control is assured. When peritonitis is diffuse, piperacillin/ tazobactam, $3^{\text {rd }}$ generation cephalosporines/fluorochinolones and metronidazol, $4^{\text {th }}$ generation cephalosporines, a carbapenem or tigecycline should be admitted for 5 to 7 days.

In high risk patients and health care associated peritonitis with a higher suspicion of resistant pathogens, an antibiotic therapy of 10 to 14 days with e.g. piperacillin/tazobactam, a $4^{\text {th }}$ generation cephalosporin and metronidazol, a carbapenem or tigecycline is recommended.

In TP the antibiotic choice should be based on microbial resistance analysis with inclusion of candida spp. (Table 6; Antibiotic treatment recommendations) $[9,66]$.

\section{SumMary AND CONCLUSIONS}

In ICU patients the augmenting rate of infections with resistant bacteria and fungi is a serious problem. In addition to the control of vital parameters and organ function during ICU stay, the interpretation of resistance analyses from the microbiology is getting more important than it was in the past. To assure patients' survival after a successful operation surgeons and intensive care physicians must be aware of the diversity of resistant bacterial species and fungi to choose the best antimicrobial agent out of the different classes of antibiotics. A major concern in the future will be that physicians will be confronted with an increasing rate of resistant micro-organisms with a decreasing number of new antibiotic agents.

At the moment the two principles surgical treatment and intensive care medicine do not need a substantial change. However the third part in the treat- ment of SP, the use of antibiotics, has to be improved. Since the rate of resistant bacteria in SP is $30 \%-40$ $\%$, physicians should use the vast diversity of differently acting antibiotics to optimise the therapy of $\mathrm{pa}$ tients with SP [14]. Therefore, the initial treatment of patients at risk for infections with MDR germs should include a broad spectrum antibiotic, covering the most frequent resistant bacteria in SP.

Tertiary peritonitis still is a major problem in ICU patients and is associated with unsatisfactory too high morbidity and mortality. Patients at risk for the development of TP have a high Mannheim peritonitis index at the index operation and higher SAPS II scores during ICU stay [18]. The treatment strategy for patients with TP consists in antibiotic and antifungal therapy in accordance to the resistance analyses from the microbiology.

The best description for the antibiotic treatment in the future has been summarized by the "Tarragona strategy" (Table 7, "Tarragona strategy") [67]. The initial empiric antibiotic therapy should be calculated according to the individual patients' risk factors, with respect to the hospital specific surveillance data. The antibiotic choice should be selected out of the vast diversity of differently acting antibiotic agents to reduce the selection pressure.

The "Tarragona strategy" in detail:

Hit hard and early. The initial therapy should include high doses of broad spectrum antibiotics, even if the costs are expensive. Initial therapy should be initiated as soon as possible.

Look at your patient. In patients with community-acquired secondary peritonitis antibiotic therapy should cover Enterobacteriaceae and anaerobes. In patients with post-operative SP a shift towards more resistant species has to be expected including Gram-negative and Gram- positive species with MDR (ESBL, VRE, MRSA). The highest risk for infections with MDR pathogens exists in patients with serious co-morbidities, a recent surgical history or prior broad spectrum antibiotic therapy. Therefore, the choice of cheaper antibiotics should be reserved for "healthy" patients without serious co-morbidities.

Listen to your hospital. Antibiotic treatment modalities need a regular update according to the hospital specific surveillance data. Use broad spectrum antibiotics with wide coverage. 
Focus, focus, focus. De-escalation is indicated in stable patients in accordance to the results from the microbiology to avoid prolonged antibiotic exposure. Use the whole diversity of differently acting antibiotics to reduce the selection pressure among pathogens.

Successful treatment of cIAIs is based on the three important columns: focus elimination, intensive care management and antibiotic therapy. Resistance analyses of microbiological culture results became more important, since the rate of MDR micro-organisms increased rapidly. Intensive care physicians and surgeons must be aware of the diversity of different antibiotic classes to choose an appropriate initial therapy, based on patients' risk factors and hospital specific resistance rates. Immediate and appropriate application of antimicrobial agents is mandatory to avoid treatment failure and the development of new resistance. Further investigation from the pharmaceutical industry for the development of new antibiotics is essential to assure effective treatment options in the future. Otherwise we will end up in an a-antibiotic time.

\section{LITERATURE}

1. Barie PS, Hydo LJ, Eachempati SR. Longitudinal outcomes of intra-abdominal infection complicated by critical illness. Surg Infect (Larchmt) 2004; 5(4):365-73.

2. Dellinger EP, Wertz MJ, Meakins JL, et al. Surgical infection stratification system for intra-abdominal infection. Multicenter trial. Arch Surg 1985; 120(1):21-9.

3. Finfer S, Bellomo R, Lipman J, et al. Adult-population incidence of severe sepsis in Australian and New Zealand intensive care units. Intensive Care Med 2004; 30(4):58996.

4. Vincent JL, Rello J, Marshall J, et al. International study of the prevalence and outcomes of infection in intensive care units. Jama 2009; 302(21):2323-9.

5. Wittmann DH, Schein M, Condon RE. Management of secondary peritonitis. Ann Surg 1996; 224(1):10-8.

6. Myers E, Hurley M, O'Sullivan GC, et al. Laparoscopic peritoneal lavage for generalized peritonitis due to perforated diverticulitis. Br J Surg 2008; 95(1):97-101.

7. Penninckx FM, Kerremans RP, Lauwers PM. Planned relaparotomies in the surgical treatment of severe generalized peritonitis from intestinal origin. World J Surg 1983; 7(6):762-6.

8. Teichmann W, Wittmann DH, Andreone PA. Scheduled reoperations (etappenlavage) for diffuse peritonitis. Arch Surg 1986; 121(2):147-52.

9. Solomkin JS, Mazuski JE, Bradley JS, et al. Diagnosis and management of complicated intra-abdominal infection in adults and children: guidelines by the Surgical Infection Society and the Infectious Diseases Society of America. Surg Infect (Larchmt); 2010; 11(1):79-109.

10. Ingraham AM, Cohen ME, Bilimoria KY, et al. Comparison of outcomes after laparoscopic versus open appendectomy for acute appendicitis at 222 ACS NSQIP hospitals. Surgery; 2010; 148(4):625-35; discussion 635-7.

11. Farthmann EH, Schoffel U. Epidemiology and pathophysiology of intraabdominal infections (IAI). Infection 1998; 26(5):329-34.

12. Calandra T, Cohen J. The international sepsis forum consensus conference on definitions of infection in the intensive care unit. Crit Care Med 2005; 33(7):1538-48.

13. Fridkin SK, Hageman JC, Morrison M, et al. Methicillinresistant Staphylococcus aureus disease in three communities. N Engl J Med 2005; 352(14):1436-44.

14. Montravers P, Lepape A, Dubreuil L, et al. Clinical and microbiological profiles of community-acquired and nosocomial intra-abdominal infections: results of the French prospective, observational EBIIA study. J Antimicrob Chemother 2009; 63(4):785-94.

15. Evans HL, Raymond DP, Pelletier SJ, et al. Diagnosis of intra-abdominal infection in the critically ill patient. Curr Opin Crit Care 2001; 7(2):117-21.

16. Reemst PH, van Goor H, Goris RJ. SIRS, MODS and tertiary peritonitis. Eur J Surg Suppl 1996(576):47-8; discussion 49 .

17. Nathens AB, Rotstein OD, Marshall JC. Tertiary peritonitis: clinical features of a complex nosocomial infection. World J Surg 1998; 22(2):158-63.

18. Chromik AM, Meiser A, Holling J, et al. Identification of patients at risk for development of tertiary peritonitis on a surgical intensive care unit. J Gastrointest Surg 2009; 13(7):1358-67.

19. Menichetti F, Sganga G. Definition and classification of intra-abdominal infections. J Chemother 2009; 21 Suppl $1: 3-4$.

20. Weigelt JA. Empiric treatment options in the management of complicated intra-abdominal infections. Cleve Clin J Med 2007; 74 Suppl 4:S29-37.

21. Marshall JC, Innes M. Intensive care unit management of intra-abdominal infection. Crit Care Med 2003; 31(8): 2228-37.

22. Herzog T, Belyaev O, Muller CA, et al. Bacteribilia after preoperative bile duct stenting: a prospective study. J Clin Gastroenterol 2009; 43(5):457-62.

23. Roehrborn A, Thomas L, Potreck O, et al. The microbiology of postoperative peritonitis. Clin Infect Dis 2001; 33(9):1513-9.

24. Montravers P, Gauzit R, Muller C, et al. Emergence of antibiotic-resistant bacteria in cases of peritonitis after intraabdominal surgery affects the efficacy of empirical antimicrobial therapy. Clin Infect Dis 1996; 23(3):486-94.

25. Burnett RJ, Haverstock DC, Dellinger EP, et al. Definition of the role of enterococcus in intraabdominal infection: analysis of a prospective randomized trial. Surgery 1995; 118(4):716-21; discussion 721-3.

26. Seguin P, Laviolle B, Chanavaz C, et al. Factors associated with multidrug-resistant bacteria in secondary peritonitis: impact on antibiotic therapy. Clin Microbiol Infect 2006; 12(10):980-5.

27. Swenson BR, Metzger R, Hedrick TL, et al. Choosing antibiotics for intra-abdominal infections: what do we mean by "high risk"? Surg Infect (Larchmt) 2009; 10(1):29-39.

28. Seguin P, Fedun Y, Laviolle B, et al. Risk factors for multidrug-resistant bacteria in patients with post-operative peritonitis requiring intensive care. J Antimicrob Chemother 2010; 65(2):342-6.

29. Falagas ME, Karageorgopoulos DE. Extended-spectrum beta-lactamase-producing organisms. J Hosp Infect 2009; 73(4):345-54.

30. Eagye KJ, Kim A, Laohavaleeson S, et al. Surgical site infections: does inadequate antibiotic therapy affect patient outcomes? Surg Infect (Larchmt) 2009; 10(4):323-31.

31. Haddadin AS, Fappiano SA, Lipsett PA. Methicillin resistant Staphylococcus aureus (MRSA) in the intensive care unit. Postgrad Med J 2002; 78(921):385-92.

32. Cainzos M. Review of the guidelines for complicated skin and soft tissue infections and intra-abdominal infections-are they applicable today? Clin Microbiol Infect 2008; 14 Suppl 6:9-18.

33. Schneider CR, Buell JF, Gearhart M, et al. Methicillin-resistant Staphylococcus aureus infection in liver transplantation: a matched controlled study. Transplant Proc 2005; 37(2):1243-4.

34. Hoban DJ, Bouchillon SK, Hawser SP, et al. Susceptibility of gram-negative pathogens isolated from patients with complicated intra-abdominal infections in the United States, 2007-2008: results of the Study for Monitoring 
Antimicrobial Resistance Trends (SMART). Antimicrob Agents Chemother; 54(7):3031-4.

35. Pitout JD, Laupland KB. Extended-spectrum beta-lactamase-producing Enterobacteriaceae: an emerging publichealth concern. Lancet Infect Dis 2008; 8(3):159-66.

36. Barie PS, Christou NV, Dellinger EP, et al. Pathogenicity of the enterococcus in surgical infections. Ann Surg 1990; 212(2):155-9.

37. Nichols RL, Muzik AC. Enterococcal infections in surgical patients: the mystery continues. Clin Infect Dis 1992; 15(1):72-6.

38. Chatterjee I, Iredell JR, Woods M, Lipman J. The implications of enterococci for the intensive care unit. Crit Care Resusc 2007; 9(1):69-75.

39. Sitges-Serra A, Lopez MJ, Girvent M, et al. Postoperative enterococcal infection after treatment of complicated intra-abdominal sepsis. Br J Surg 2002; 89(3):361-7.

40. de Vera ME, Simmons RL. Antibiotic-resistant enterococci and the changing face of surgical infections. Arch Surg 1996; 131(3):338-42.

41. Yellin AE, Heseltine PN, Berne TV, et al. The role of Pseudomonas species in patients treated with ampicillin and Sulbactam for gangrenous and perforated appendicitis. Surg Gynecol Obstet 1985; 161(4):303-7.

42. Szeto CC, Kwan BC, Chow KM, et al. Recurrent and relapsing peritonitis: causative organisms and response to treatment. Am J Kidney Dis 2009; 54(4):702-10.

43. Taccone FS, Rodriguez-Villalobos H, De Backer D, et al. Successful treatment of septic shock due to pan-resistant Acinetobacter baumannii using combined antimicrobial therapy including tigecycline. Eur J Clin Microbiol Infect Dis 2006; 25(4):257-60.

44. Blot S, De Waele JJ. Critical issues in the clinical management of complicated intra-abdominal infections. Drugs 2005; 65(12):1611-20.

45. Christou NV, Turgeon P, Wassef R, et al. Management of intra-abdominal infections. The case for intraoperative cultures and comprehensive broad-spectrum antibiotic coverage. The Canadian Intra-abdominal Infection Study Group. Arch Surg 1996; 131(11):1193-201.

46. Inui T, Haridas M, Claridge JA, Malangoni MA. Mortality for intra-abdominal infection is associated with intrinsic risk factors rather than the source of infection. Surgery 2009; 146(4):654-61; discussion 661-2.

47. Wacha H, Hau T, Dittmer R, Ohmann C. Risk factors associated with intraabdominal infections: a prospective multicenter study. Peritonitis Study Group. Langenbecks Arch Surg 1999; 384(1):24-32.

48. Nystrom PO, Bax R, Dellinger EP, et al. Proposed definitions for diagnosis, severity scoring, stratification, and outcome for trials on intraabdominal infection. Joint Working Party of SIS North America and Europe. World J Surg 1990; 14(2):148-58.

49. Linden PK, Moellering RC, Jr., Wood CA, et al. Treatment of vancomycin-resistant Enterococcus faecium infections with quinupristin/dalfopristin. Clin Infect Dis 2001; 33(11):1816-23.

50. Ziglam H. Daptomycin and tigecycline: a review of clinical efficacy in the antimicrobial era. Expert Opin Pharmacother 2007; 8(14):2279-92.

51. Van Laethem Y, Sternon J. [Linezolid (Zyvoxid)]. Rev Med Brux 2004; 25(1):47-50.

52. Hasper D, Schefold JC, Baumgart DC. Management of severe abdominal infections. Recent Pat Antiinfect Drug Discov 2009; 4(1):57-65

53. Oliva ME, Rekha A, Yellin A, et al. A multicenter trial of the efficacy and safety of tigecycline versus imipenem/ cilastatin in patients with complicated intra-abdominal in fections [Study ID Numbers: 3074A1-301-IWW; ClinicalTrials.gov Identifier: NCT00081744]. BMC Infect Dis 2005; 5:88.
54. Babinchak T, Ellis-Grosse E, Dartois N, et al. The efficacy and safety of tigecycline for the treatment of complicated intra-abdominal infections: analysis of pooled clinical trial data. Clin Infect Dis 2005; 41 Suppl 5:S354-67.

55. Fomin P, Beuran M, Gradauskas A, et al. Tigecycline is efficacious in the treatment of complicated intra-abdominal infections. Int J Surg 2005; 3(1):35-47.

56. Sader HS, Jones RN, Dowzicky MJ, Fritsche TR. Antimicrobial activity of tigecycline tested against nosocomial bacterial pathogens from patients hospitalized in the intensive care unit. Diagn Microbiol Infect Dis 2005; 52(3):203-8.

57. Biedenbach DJ, Beach ML, Jones RN. In vitro antimicrobial activity of GAR-936 tested against antibiotic-resistant gram-positive blood stream infection isolates and strains producing extended-spectrum beta-lactamases. Diagn Microbiol Infect Dis 2001; 40(4):173-7.

58. Lee C. Therapeutic challenges in the era of antibiotic resistance. Int J Antimicrob Agents 2008; 32 Suppl 4:S1979.

59. French GL. What's new and not so new on the antimicrobial horizon? Clin Microbiol Infect 2008; 14 Suppl 6:1929.

60. Dupont $H$. The empiric treatment of nosocomial intraabdominal infections. Int J Infect Dis 2007; 11 Suppl 1:S1-6.

61. Mazuski JE, Sawyer RG, Nathens AB, et al. The Surgical Infection Society guidelines on antimicrobial therapy for intra-abdominal infections: evidence for the recommendations. Surg Infect (Larchmt) 2002; 3(3):175-233.

62. Sandiumenge A, Diaz E, Rodriguez A, et al. Impact of diversity of antibiotic use on the development of antimicrobial resistance. J Antimicrob Chemother 2006; 57(6): 1197-204

63. Kumar A, Roberts D, Wood KE, et al. Duration of hypotension before initiation of effective antimicrobial therapy is the critical determinant of survival in human septic shock. Crit Care Med 2006; 34(6):1589-96.

64. Krobot K, Yin D, Zhang Q, et al. Effect of inappropriate initial empiric antibiotic therapy on outcome of patients with community-acquired intra-abdominal infections requiring surgery. Eur J Clin Microbiol Infect Dis 2004; 23(9):682-7.

65. Kumar A, Ellis P, Arabi Y, et al. Initiation of inappropriate antimicrobial therapy results in a fivefold reduction of survival in human septic shock. Chest 2009; 136(5):123748.

66. Bodmann KF. [Complicated intra-abdominal infections: pathogens, resistance. Recommendations of the Infectliga on antbiotic therapy]. Chirurg; 2010; 81(1):38-49.

67. Sandiumenge A, Diaz E, Bodi M, Rello J. Therapy of ventilator-associated pneumonia. A patient-based approach based on the ten rules of "The Tarragona Strategy". Intensive Care Med 2003; 29(6):876-83.

Received: November 14, 2010 / Accepted: November 15, 2010

Address for correspondence:

Prof. Waldemar Uhl, M.D., FRCS

Department of Surgery

St. Josef Hospital Bochum

Hospital of the Ruhr-University

Gudrunstr. 56

D-44791 Bochum

Germany

Phone: + 492345092211

Fax: + 492345092209

E-mail: w.uhl@klinikum-bochum.de 